\title{
Obstacles to Effective Utilization of Communication Channels by the Chiefs and Assistant Chiefs in Kipkarren Division, Nandi County, Kenya
}

\author{
Biwott Edith Jelagat \\ PHD student, Department of Communication Studies, Moi University; P. O. Box 7536-30100, Eldoret, Kenya
}

\begin{abstract}
This paper examines the obstacles to effective utilization of available communication channels by the Chiefs and Assistant Chiefs in Kenya. The study employed a census approach where a sample of 89 respondents was used. Of these, 25 were Chiefs and Assistant Chiefs and 64 were primary and secondary school head teachers. Questionnaires and observation checklist formed the primary data collection instruments. The data collected was analyzed using descriptive statistics. The main findings of the study were that although there were other channels of communication, the oral channel of communication was the most employed by the Chiefs and Assistant Chiefs. The study established that lack of Information Communication Technology (ICT) tools was the main obstacle to effective utilization of a number of ICT-based communication channels. Arising from the findings, it was concluded that reliance on the oral medium of communication is not the most effective in communicating information to the public. It is recommended that the government should invest in modern communication channels and other infrastructure, including community radio to enhance communication channels at the grassroots level. The findings are useful to the Kenyan government in setting up policies and infrastructure to facilitate use of ICT tools in the grass root levels amidst the devolved system of government.
\end{abstract}

Keywords: Barriers, Effective Utilization, Communication Channels, chiefs, Kipkarren Division, Nandi County, Kenya

\section{Introduction}

According to [1], the Ministry of State for Provincial Administration and Internal Security, which was under the Office of the President (before the advent of the current constitution in Kenya), traces its origin to the $18^{\text {th }}$ century during the establishment of colonial rule. During this period, the main functions of the Provincial administrators were to collect taxes, maintenance of law and order and pacification of the natives in the colony. It also provided judicial services (lay services) and participated in legislative matters in Local Authorities. The Chiefs and Assistant Chiefs were then instruments used by the colonialists to effect colonial Government policies.

The Provincial Administration (PA) was the most visible arm of the Executive in the Kenya Government, largely because its structure cascaded through Provinces, Districts, Divisions, and Locations up to Sub-location levels. However, with the scrapping off of the provincial Administration, its lower carder, in this case the Chiefs and Assistant Chiefs still stands as the representation of the central government. The Chiefs and Assistant Chiefs bring services closer to the people, especially coordination, surveillance, mobilization and dissemination of Government policies. Amidst the devolved system in Kenya, the Chiefs and Assistant Chiefs are the representation of the central government at the grass roots.

According to the Chiefs Act [2], the major functions of the Chiefs and Assistant Chiefs in articulating and implementing Government policies include the following:

- Act as a link between the citizens in the location and the Government

- Explain government policies to the citizens in the location

- Ensure that people in the location live peacefully with one another

- Encourage development projects in the location

- Control the abuse of drugs and substances

- Settle disputes between people in the location

- Mobilize people in the location to participate in development activities such as building bridges, access roads and so on

From these responsibilities, it can be discerned that Chiefs and Assistant Chiefs are central to the understanding and advancement of Government policies and the success of Central Government operations at the grassroots level. It follows, therefore, that when a new Government assumes office, the Chiefs and Assistant Chiefs must of necessity be guided in internalizing and articulating the policies of that Government so that they discharge their responsibilities more effectively. 
An understanding of the obstacles to effective communication by the Chiefs and Assistant Chiefs is crucial because it enables the various actors to interact successfully. The Chiefs and Assistant Chiefs continually need communication tools they can use to keep citizens informed about community issues and services and also for better communicating what the government is and what it does for its citizens. Other communication approaches are needed to obtain feedback and ideas about citizen concerns and needs. Perhaps most important of all are the approaches that engage citizens in decisions about community direction and improvement.

Although devolution has brought about various changes in the activities done by the Chiefs and Assistant Chiefs, it is evident that they are still the main link between the central government in Kenya and the people at the grassroots. It is the main representation of the central government in the grassroots amidst the governance of the county governments. It is thus important to explore the barriers to the effective utilization of communication channels that are available in the market as well as those availed to them by the government.

\subsection{Selection of Communication Channels}

According to [3], for the communication to be effective, the communicator has to be very careful and judicious in the choice of media, which will depend on various factors like the urgency of the message, the time available, the expenditure involved and the intellectual and emotional level of the receiver. The channel selected for communication should also adhere to various principles for it to be effective. According to [3], there are several principles of communication, the scientific aspects that must be taken into account in all media of communication: clarity, completeness, conciseness, consideration, courtesy and correctness. Saleemi [3] says that these principles help to make various forms of communication more effective. In the choice of the channel of communication, these aspects should be considered, failure to which will lead to communication break-down; this means that the existence of a given channel does not guarantee effective communication if the principles are down played. Thus, the disregard of the principles of communication may bring about possible obstacles to effective utilization of channels of communication.

Channel selection can be done based on two ideas. First, it can be done focusing on the characteristics of the media themselves [4]. It can also be done focusing on the social context of communication [5]. With the help of Media Richness Theory [4], it can be realized that the appropriate choice of communication channel contributes significantly, along with the words, to the success of a message. The selection of a communication channel is also influenced by virtue of whether it is a formal or an informal communication channel. Formal channels follow the chain of command established by the hierarchy of authority on the other hand informal channels do not adhere to the hierarchy of authority. Grapevine is an example of an informal channel through which rumors and unofficial information pass through. Appropriate choice of the communication channel helps senders communicate clearly, saving them and their organization or business time and money. In this regard, examining various communication channels to understand their appropriate use is important.

It is thus evident that there are various channels of communication and selection of appropriate channels is paramount. Proper selection and use of the communication channels ensure that in the end, the message has been sent and received, the meaning has been decoded and the destination has acted (the behavior of the destination has changed) in the manner intended by the source. Without proper selection, the message will not reach its intended audience. This is why this study surveyed the channels which were available for the Chiefs and Assistant Chiefs to use and their effectiveness in performing their duties. Therefore, in analyzing the various channels employed by the Chiefs and Assistant Chiefs, the research focused on the channels' advantages and disadvantages as well as their applicability. The author also looked at the channel selection in various social contexts of communication.

\subsection{Barriers to Effective Communication}

The process of communicating is at times interfered with and as a result the objectives are not met. Receivers may in turn not get the intended message. According to [6], there are three reasons receivers may not get the intended message: first is selective attention, in which they will not notice everything around them; second is selective distortion in which they will twist the message to hear what they want to hear, and third, selective recall, in which they will retain only a fraction of the messages that reach them. Kotler [6]further, presenting Schramm's view, argues that the likelihood of attention is a function of reward, punishment and expenditure of effort. In essence, if your message is easy to understand and offers high rewards to the receiver, you are more likely to get the receiver's attention.

In each process of communication - encoding, transference and decoding - there may be a possibility of interference which may hamper the communication process. This interference is referred to as noise. Noise can appear anywhere in the communication system and distort the process. According to [7], there are three types of noise: channel, psychological and language. Channel noise refers to physical interference; psychological noise occurs as a result of the relationship between sender and receiver causing the receiver to 
read something else into the sender's message, whereas language noise arises from a mismatch of code between sender and receiver.

Harrison [8]discusses eight barriers to communication as: fields of experience - senders and receivers can only communicate effectively within the area covered by their common fields of experience, i.e. the greater the commonality of experience the more effective communication is likely to be; value judgment - the receiver's attitude towards the source of the information will affect the way he treats the message received (the most important factors in source credibility are expertise, trustworthiness and likeability; mismatching mismatch between the medium chosen and the message it relates to, and language problems such as semantic issues, selectivity, status differences, time constrain and overload.

Identifying and understanding the various barriers to effective communication makes it easy to come up with ways to reduce and eliminate these barriers. Effective communication occurs when someone's intended meaning successfully and accurately reaches the target person. It is with this in mind that the research was able to analyze the various barriers to adoption of various channels of communication.

\subsection{Limitations of the Study}

Ideally, the study should have been conducted in all the Administrative areas in the country to enable the author get enough data to reflect the situation as it is in the whole country, but due to time as well as financial constraints, the author was prevented from achieving this.

\section{Materials And Methods}

The research design used in the study was descriptive survey. Descriptive research studies are concerned with describing the characteristics of a particular individual, or a group [9]. In the study, the descriptive survey design was found suitable as the research aimed at collecting information from the respondents on their attitudes and opinions in relation to the way Chiefs and Assistant Chiefs communicate. Survey research design was used because the population studied was too large to be observed directly and thus enabled the author to use questionnaires as a method of data collection. The survey research was therefore useful because of the economy of taking a sample of the population to generalize results for the whole population.

The research was carried out in Kipkarren Division of Nandi North District, Rift Valley Province in Kenya. Nandi North District (found in the current, Nandi County) lies on the Western part of Rift Valley Province and occupies 1,482 square kilometres [10]. It has five Administrative divisions, namely Kapsabet, Kilibwoni, Kosirai, Kabiyet and Kipkarren. The District was created from the larger Nandi and has four main features, namely the rolling hills to the west, the Kapsabet plateau, the highlands and Kingwal swamp in the Baraton/Chepterit area. Kipkarren Division has six locations and fourteen sub-locations. This area was taken to represent other Administrative areas in the country. The author is familiar with the area and thus enabled easy collection of data. It was therefore believed that the study gave a wide and varied view of the problem under study. This study targeted the Chiefs and Assistant Chiefs and all primary and secondary school head teachers in Kipkarren Division who acted as a representation of the publics which interacted with the Chiefs and Assistant Chiefs within the Division on a regular basis. They were basically involved as key informants in the study.

As noted by [11], factors such as expense, time and accessibility frequently prevent researchers from gaining information from the whole population. Therefore, there is need to obtain data from a smaller group or subset of the total population in such a way that the knowledge gained is representative of the total population under study. However, in the study the author employed census sampling. A census sample gathers data on every member of the population. A census is an attempt to gather information from each and every person of interest, that is, all the study targets. This sampling technique was chosen because the entire population was sufficiently small, and the author could therefore include the entire population in the study. The data collection instruments tools used in the study were questionnaires, and observation checklist.

\section{Results And Discussion}

\subsection{Obstacles to Effective Utilization of the Channels of Communication}

Understanding the various obstacles to effective utilization of the communication channels determines a lot in the choice of the communication channel to be employed. As a result, the study sought to find out from the respondents some of the obstacles to effective utilization of communication channels by the Chiefs and Assistant Chiefs in Kipkarren Division.

The first question sought to find out how the respondents rated the use of the available channel of communication. The head teachers were asked to rate the general attendance of Chiefs and Assistant Chiefs' meetings they had either participated in or they had witnessed its attendance by the public in the Division. From the findings of the study, $37.5 \%$ of the respondents rated the attendance of meetings convened by Chiefs and Assistant Chiefs as fair; however, the majority (62.5\%) either rated the attendance as poor or very poor. It can 
be noted here that none of the respondents rated the attendance meetings convened by Chiefs and Assistant Chiefs as good or excellent.

Table 1: Head Teachers' rating of Attendance of Chiefs and Assistant Chiefs' Meetings

\begin{tabular}{lccc}
\hline Rating & Frequency & of & rating \\
& Percentage & & \\
Excellent & Nil & \\
Good & Nil & \\
Fair & $37.5 \%$ & \\
Poor & $37.5 \%$ & \\
Very poor & $25 \%$ & \\
Total & $\mathbf{1 0 0 \%}$ & \\
\hline
\end{tabular}

The same question was posed to the Chiefs and Assistant Chiefs who convened the meetings. This was meant to give the researcher a chance to compare the responses of those who convened the meetings and those invited so as to avoid any prejudice. From the findings of the study, $68 \%$ of the Chiefs and Assistant Chiefs said it was poorly attended, $28 \%$ said it was fairly attended whereas only $4 \%$ responded that the attendance was good. None admitted an excellent attendance or very poor attendance. This is shown in Fig.1.

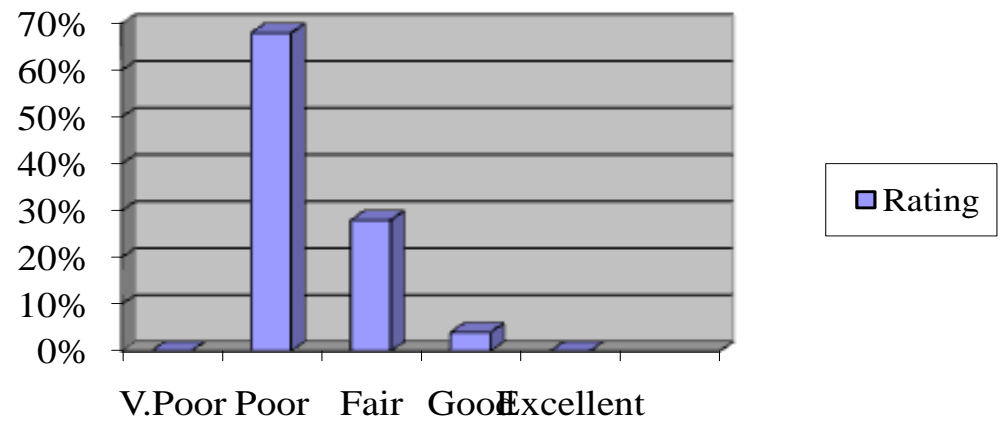

Figure 1: Attendance of Meetings as rated by the Chiefs and Assistant Chiefs

From the responses given by both the Chiefs and Assistant Chiefs as well as the head teachers, more than half of them rated the attendance as poorly attended. The meetings convened by the Chiefs and Assistant Chiefs were in general poorly attended. This was further confirmed after the researcher attended a number of meetings convened by the Chiefs and Assistant Chiefs in the Division. It was observed that the meetings were attended by adults, mainly senior men; lacking in attendance were youths and young women. It was, therefore, be concluded that the meetings convened by Chiefs and Assistant Chiefs in Kipkarren Division were poorly attended.

From the two Table 1 and Fig. 1, above and from the observations made by the researcher, it was concluded that the majority of the residents did not attend Chiefs and Assistant Chiefs meetings. Most of the respondents stated that poor attendance of meetings was due to unawareness of meetings (62.5\%). Other reasons given for poor attendance of the meetings were disinterest on the meeting or whatever the administrators were to say $(6.25 \%)$; others stated that bad relationship between the administrators and the public (18.75\%), and some people were just unwilling or committed in other duties (12.5\%). These are illustrated in Table 2.

Table 2: Reasons for Ratings on Attendance

\begin{tabular}{|c|c|}
\hline Reason for rating & $\begin{array}{l}\text { Frequency of rating in } \\
\text { Percentage }\end{array}$ \\
\hline Unaware & $62.5 \%$ \\
\hline Disinterest on the meeting & $6.25 \%$ \\
\hline Bad relationship & $18.75 \%$ \\
\hline Unwilling & $12.5 \%$ \\
\hline Total & $100 \%$ \\
\hline
\end{tabular}

According to [12], 'people today have many demands on their time; so any task that is time-consuming is less likely to win acceptance.' Thus it was concluded that due to the fact that barazas and other meetings convened by Chiefs and Assistant Chiefs are time-consuming, at times the citizens in Kipkarren Division were not willing to sacrifice their time to attend the meetings.

The respondents were asked to give reasons for the minimal use of ICT tools, and $50 \%$ attributed it to unavailability of the ICT tools and electricity, $43.75 \%$ attributed it to lack of knowledge by the officers whereas $6.25 \%$ pointed the problem to unavailability of funds to run the facilities. 
Table 3: Reasons for Minimal Use of ICT Tools

\begin{tabular}{lcc}
\hline Reason for minimal use & $\begin{array}{l}\text { Frequency of } \\
\text { Percentage }\end{array}$ & rating in \\
\hline Unavailability of the tools and & $50 \%$ \\
electricity & \\
Lack of knowledge & $43.75 \%$ \\
Unavailability of funds & $6.25 \%$ \\
$\quad$ Total & $\mathbf{1 0 0 \%}$ \\
\hline
\end{tabular}

The use of the ICT tools can only be achieved if those who are using them know how to use them. Knowledge of ICT in this study's case was in relation to the how to use a computer and all its application. A majority of the respondents $(68 \%)$ admitted having basic knowledge of ICT and only $32 \%$ responded that they had no knowledge of ICT. It is important to note that none admitted being very conversant with ICT. This is illustrated in Fig. 2 below.

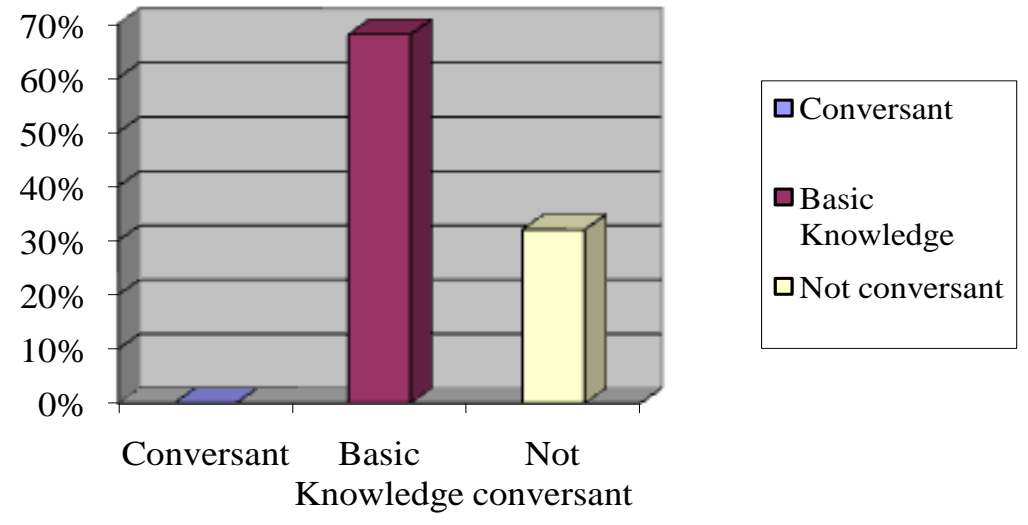

Figure 2: Respondents' ICT Knowledge

From the study observations, it was evident that th lack of electricity in most offices hampered the adoption of ICT. This is in agreement with [13] who argue that, irregular or non-existent electricity supplies are common feature of the sub-Saharan landscape and a major barrier to an increased use of ICTs, especially outside the major towns. Many countries have extremely limited power distribution networks, which do not penetrate significantly into rural areas, and power sharing (regular power outages for many hours) is a regular occurrence, even in some capital cities such as Accra and Dar es Salaam. Furthermore, most tax regimes still treat ICTs as luxury items, which makes these almost exclusively imported commodities all the more expensive, and thus unobtainable by the majority.

Thus it is evident that lack of electricity hampered the availability and use of ICT tools in the area and thus it being unused by the Chiefs and Assistant Chiefs. It was therefore concluded that lack of tools is a major reason for not using ICT, and even if they were to be availed, some facilities like the computers and printers still would not work due to lack of electricity in Kipkarren Division. In the places where they were found, quite a number of the administrators admitted that they lacked the knowledge on how to use or operate the gadgets, and this means, unless they go for a formal training, they might never be able to use them fully.

The public's use of suggestion boxes was poor according to all the 25 respondents (Chiefs and Assistant Chiefs). They gave a reason for this poor use ranging from illiteracy, lack of knowledge on its availability, and ignorance on its importance. Thus it is correct to say that the inappropriate use of the suggestion boxes limited its usefulness as a channel of communication. Moreover, it is not enough to have suggestion boxes, there is need for the Chiefs and Assistant Chiefs to educate its publics on the importance and use of suggestion boxes.

The respondents were asked to state the language which the Chiefs and Assistant Chiefs employed most and 50\% indicated vernacular and Kiswahili was the most prevalent, $31.25 \%$ said it was only Kiswahili, whereas $18.75 \%$ said that vernacular was the most prevalent language. 
Table 4: Language of Communication according to Head Teachers

\begin{tabular}{lcl}
\hline Language & Frequency of rating in \\
& Percentage & \\
\hline Vernacular \& Kiswahili & $50 \%$ & \\
Kiswahili & $31.25 \%$ & \\
Vernacular only & $18.75 \%$ & \\
Total & $\mathbf{1 0 0 \%}$ & \\
\hline
\end{tabular}

Out of the respondents from the Chiefs and Assistant Chiefs, a majority of them (84\%) of them admitted using Kiswahili and vernacular in most of their meetings, whereas $12 \%$ admitted using only vernacular and only $4 \%$ of the respondents admitted using only Kiswahili. Since the language used is a very important aspect of communication, there is need for the sender and the receiver of message to understand each other well so that the intended message may be put across. Based on the findings of the study, language was not a problem since the area covered consists mainly of one ethnic group that shared in a single vernacular language. Kiswahili being a national language, majority also understand it, and this can explicitly explain why most of the Chiefs and Assistant Chiefs preferred using both Kiswahili and the local vernacular language.

Asked to judge the communication competence of the Chiefs and Assistant Chiefs, the findings indicate that the competence of the Chiefs and Assistant Chiefs was low with less than less than half rating it as good. Presented with a likert scale of very good, good, average, poor and very poor, $35.94 \%$ indicated that the Chiefs and Assistant Chiefs communication competence was average, $32.81 \%$ indicated that the Chiefs and Assistant Chiefs' communication competence was good, $20.31 \%$ indicated that the Chiefs and Assistant Chiefs communication competence was poor whereas $10.94 \%$ indicated that the Chiefs and Assistant Chiefs communication competence was very poor. This is illustrated in Fig. 3.

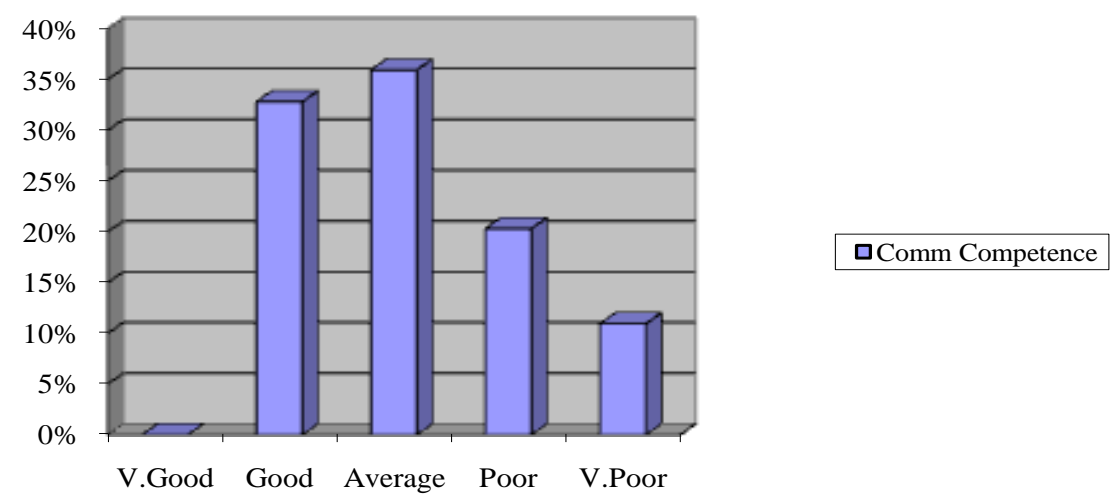

Figure 3: Communication Competence of the Chiefs and Assistant Chiefs as rated by Head Teachers

It can be noted here that none of the respondents rated the competence of the Chiefs and Assistant Chiefs as very good. It was therefore concluded that the communication competence of the Chiefs and Assistant Chiefs still needs to be improved.

\section{Conclusion And Recommendations}

From the study findings on the obstacles to the utilization of the communication channels by the Chiefs and Assistant Chiefs, it is clear that lack of ICT tools as well as lack of technological know-how poses a challenge to the embracing of these ICTs. From the study, it emerged that the changing social trends have also proved an obstacle in the use of some channels of communication; various technological advancements and the fact that many people are now in formal employment and thus cannot find time to attend some meetings are some of the contributing factors. Other obstacles to utilization of the communication channels by the Chiefs and Assistant Chiefs were unawareness of the meetings by the publics, the public's disinterest in the meetings convened by the Chiefs and Assistant Chiefs and bad relationship between the Administrators and the publics.

The study found out that the some obstacles to embracing some communication channels were caused by lack of adequate infrastructure. The government should establish infrastructure to ensure that the various ICT channels are embraced at the grassroot levels. This will also include the provision of electricity through the rural electrification program to all the Chiefs and Assistant Chiefs offices. The Chiefs and Assistant Chiefs should 
each be given funds to procure basic communication tools such as notice boards, suggestion boxes and mobile phones.

The study found out that lack of technological know-how posed a challenge in the adoption of some advanced communication channels. The government should invest in training both the Chiefs and Assistant Chiefs and the general public in the various available communication channels. Most of the chiefs and assistant chiefs indeed do not have training on use of modern communication channels. It is thus recommended that they be inducted through seminars or even short courses on use and management of modern communication tools. The training of the chiefs and assistant chiefs

\section{References}

[1] Government of Kenya, Ministry of State for Provincial Administration and Internal Security. The Kenya Government Strategic Plan, 2005/6-2009/10. Nairobi: Government Printers.

[2] Government of Kenya Chiefs Act. (Nairobi: Government Printers, 1998)

[3] N. A. Saleemi, Business communication and report writing simplified. (Nairobi: N.A Saleemi Publishers, 1997).

[4] R. L., Daft, \& R. H. Lengel, Organizational information requirements, media richness and structural design, Management Science, 32(5), 1986, 554-571.

[5] J. Fulk, C. W. Steinfield, J. Schmitz, and J. G Power,. A social information processing model of media use in organizations, Communication Research, 14(5), 1987, 529-552.

[6] Kotler, Marketing Management. (Englewood Cliffs, NJ: Prentice Hall, 1984).

[7] D. Bernstein, Company Image and Reality. (London: Cassell, 1986).

[8] S. Harrison, Public Relations: An Introduction ( $2^{\text {nd }}$ ed.).(United Kingdom: South -Western Cengage Learning, 2000).

[9] C. R. Kothari, Research Methodology, Methods and Techniques (2 $2^{\text {nd }}$ ed.). (New Delhi: New Age International Publishers, 2004)

[10] Government of Kenya, Sessional Paper No. 1.(Nairobi: Government Printers, 2005).

[11] J. E. Cohen, Human Population: The Next Half-Century. Science, 302, 2003, 1172.

[12] S. Larkin, \& T. J. Larkin, Change the Communication Channel: Web, Paper or Face-to-face. Communication World Magazine, 22(6). November/December 2005.

[13] UNESCO (1999). World Information and Communication Report 1999-2000. Retrieved on August 12, 2010 from http://www.unesco.org/webworld/wcir/en/report/html 